\title{
Desestabilizar la mirada: reactualización del mito griego de Tiestes en la puesta de Emilio García Wehbi
}

\author{
Matías Corradi \\ Facultad de Filosofía y Letras - UBA \\ matias_corradi@yahoo.com
}

Fecha de recepción: 06/07/2018. Fecha de aceptación: 27/10/2018

\section{Resumen}

A partir del mito antiguo de Tiestes y haciendo pie en la tragedia senecana del siglo I D.C. la puesta que García Wehbi monta en el Teatro Nacional Cervantes deconstruye ciertos aspectos clave de la historia occidental cristiana, entre ellos, el sistema patriarcal. Este artículo se propone analizar, desde una perspectiva semiológica, la abundancia de citas de índole cultural (artística, religiosa, etc.) insertas en los diferentes lenguajes escénicos, para validar la idea de "collage intertextual" como principio constructivo de su poética y herramienta principal para desestabilizar el ordenamiento simbólico dominante.

\section{Destabilizing Perspectives: Bringing the Greek Myth of Thyestes Up to Date in Emilio García Wehbi's Staging}

\begin{abstract}
On the basis of the Myth of Thyestes and the Senecan tragedy, Garcia Wehbi's play Tiestes y Atreo staged at the Cervantes National Theatre deconstructs a number of key elements of Western-Christian history, such as patriarchy. This article undertakes a semiologic analysis of the various cultural referents (artistic, religious) inserted into the script in order to show how the concept of "inter-textual collage" underpins the poetry of the play, while it constitutes Garcia Wehbi's main tool to destabilise the dominant symbolic order.
\end{abstract} Palabras clave Tragedia Wehbi Patriarcado Occidente Mito Tiestes y Atreo

\section{Introducción}

Vamos a analizar de que manera el director Emilio García Wehbi reformula, en el contexto contemporáneo, el mito originario de Tiestes (y Atreo), partiendo de la obra clásica que escribiera Séneca en el primer siglo de nuestra era. Para ello, abordaremos

Keyword Tragedy Wehbi Patriarchy West Myth Tiestes y Atreo 
su marco de proveniencia, el sistema de signos escénicos y la multiplicidad de recursos culturales y artísticos (lingüísticos, plásticos, musicales, dancísticos, etc.) empelados por el autor, para configurar la puesta en escena, estrenada en el Teatro Nacional Cervantes de buenos Aires, en 2018. Esto nos servirá para sostener la noción de collage intertextual como principio constructivo que busca desestructurar, a través del dispositivo estético, la opresión histórica que ejerce el patriarcado en la cultura occidental. Finalmente, veremos qué correspondencias se pueden establecer con algunos procedimientos característicos de la escena posdramática.

\section{Primus inter pares}

Comencemos por delimitar el marco histórico a partir del cual Wehbi retoma el argumento de su obra. La tragedia grecolatina que escribió Séneca (4 A.C. - 65 D.C.) es la única pieza completa que nos legó la antigüedad sobre el mito de Tiestes; previamente lo habían hecho Eurípides y Sófocles, pero de estas solo han quedado algunos fragmentos del primero. La misma trata del conflicto entre hermanos por la posesión del trono de Micenas para ofrecer, en los tiempos convulsos del imperio romano, una lectura moral en la que Tiestes, siguiendo el ethos estoico proclamado por el autor, representa la cara positiva, mientras que Atreo, en tanto tirano, el ángulo negativo. A este contraste evidente en el texto dramático hay que sumarle la excesiva crudeza en la narración de los acontecimientos que allí tienen lugar, en especial el hecho, por parte de Atreo, de darle de comer a su hermano, en estofado, a sus propios hijos, tema que solo volverá a representarse en el teatro isabelino mediante la truculenta tragedia shakespearana Tito Andronico que sin dudas se inspira en la obra de Séneca.

Ahora bien, la versión que lleva adelante Wehbi - al parecer según los registros históricos esta sería la primera pieza de Séneca que se representa en Argentina- se sirve de este antecedente, pero lo despoja de su carácter aleccionador, de forma tal que recupera la fuente mítica, mucho más ambigua en cuanto al quehacer ético de sus personajes. De esta forma, realiza una exégesis donde la problemática no será la disputa por el poder político entre hermanos, sino las relaciones de dominación (y finalmente de supresión), que estos establecen para con sus respectivos hijos, haciendo extensiva esta consideración hacia las mujeres, las minorías raciales, de género y todo aquel grupo social que confronte con la hegemonía masculina blanca. En este sentido, como enseguida veremos, el autor readapta de manera novedosa el material preexistente suscitando una serie de reflexiones críticas sumamente vitales en el contexto del pensamiento actual.

\section{Escila versus Caribdis}

El texto espectacular se divide en dos actos, mediados por un intervalo musical y un cuento final, cuyos nombres podemos identificar en el escenario a través de elegantes luces de neón, que hacen referencia a los peñascos sicilianos que, ya en los tiempos de Homero, eran metáfora de monstruos marinos que devoraban a los náufragos que pasaran por allí. Del mismo modo sobre el final de ambos actos serán los niños quienes resultarán fagocitados por los adultos mayores, en una clara alusión a la dificultad que tienen las nuevas generaciones de producir transformaciones, dentro del espectro social y político, cuando chocan con la tradición conservadora encarnada por las generaciones anteriores.

La primera parte, también denominada "La república de los niños", se sitúa en un lugar pos-apocalíptico, una especie de baldío donde la vegetación crece entre la carrocería de viejos autos y dentro del cual se levanta un pequeño bunker que sirve de base para una suerte de grupo comando de niñas azafatas insurrectas. En este espacio tiene lugar la 


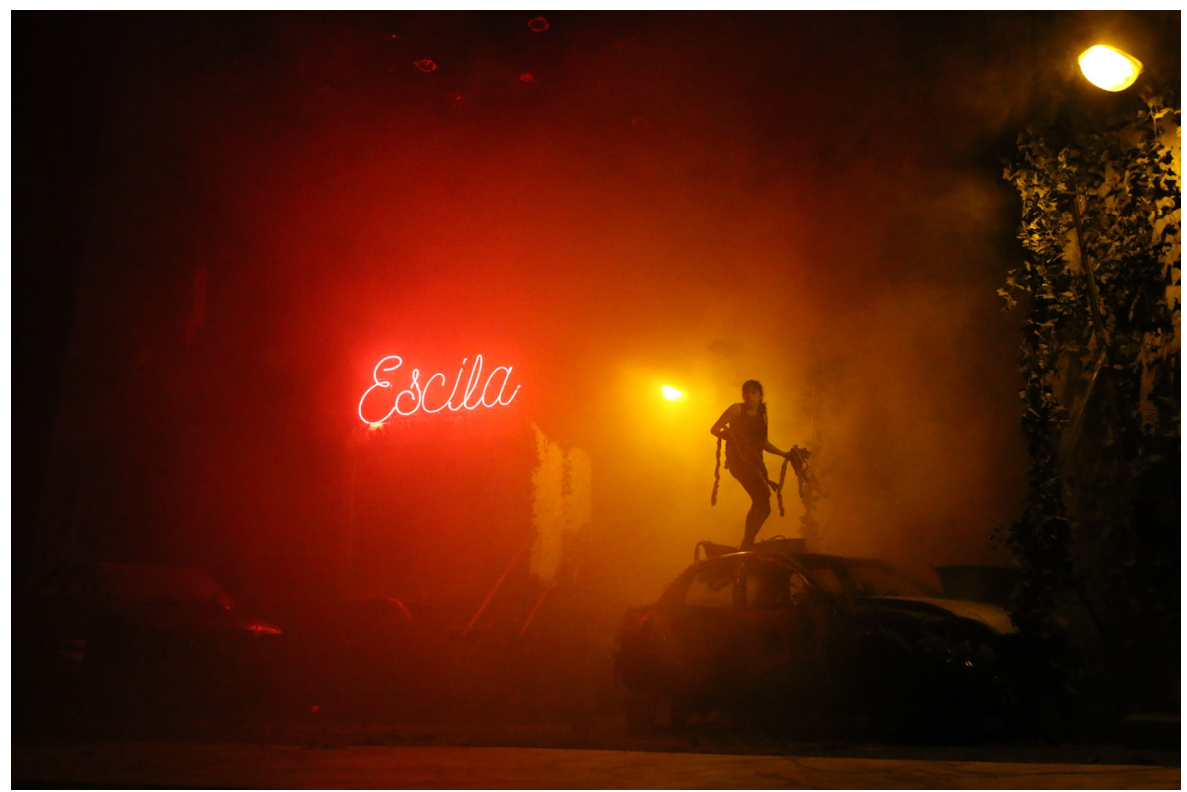

fábula infantil donde estas chicas de armas tomar, de no más de 10012 años, ajustan cuentas con el patriarcado representado por una serie de payasos deprimentes que desfilan y dinosaurios que pretenden crear el caos persiguiéndolas, pero que prontamente resultan descabezados. Entretanto, deambula entre un enjambre de tripas la Furia embarrada que, con voz potente, va dando discursos soberbios y aterradores hasta que una de las nenas, luego de esparcir una buena dosis de desodorante de ambiente, la interpela de manera irónica señalándole su condición de personaje teatral y dejándola expuesta en una posición cómica y ridícula. Sobre el final de este acto se consuma el asesinato sanguinario de las niñas en nombre de los valores cristianos (tal el sentido de la cruz enclavada e iluminada por un foco cenital mientras ocurre la masacre) entre alaridos espantosos.

Por su parte, el segundo acto llamado "El banquete" ilustra con mayor fidelidad la tragedia senecana. Allí se ve, en primer lugar, a la Furia cual Sísifo cargando sobre sus espaldas una enorme piedra; más tarde aparecen Tiestes (Maricel Álvarez) y Atreo (Analía Couceyro) prolijamente ataviados, sentados en los extremos de una larga mesa y, sobre el proscenio, sus respectivos hijos, los guardias y, a su alrededor, las niñas del primer acto. Por detrás, un ágil corifeo empuja el cordero de oro. El acto se desarrolla entre largos monólogos amenazantes enunciados alternadamente por los hermanos subidos a la mesa hasta que, en determinado momento, todos los personajes se sientan y devoran la comida. Luego se da una dinámica violenta sobre la mesa a la que le suceden los parlamentos de los guardias y los hijos (rebautizados Bulimia y Anorexia), que hablan desde las entrañas de sus padres, para finalmente colocarse una masa estirada que les oculta el rostro.

Hasta aquí la sucesión de los acontecimientos para enmarcar la propuesta del director. Ahora pasaremos a describir el funcionamiento de los diferentes signos escénicos y su articulación en el devenir dramático.

\section{Conjugación de lenguajes escénicos}

Antes que nada, resulta necesario aclarar que la abundante "polifonía informacional" (siguiendo el concepto de Barthes), que se despliega sobre el escenario, tiene por objeto promover una comunicación con el espectador donde la combinatoria de los sistemas de signos exigen un esfuerzo sostenido para lograr una comprensión más cabal del suceso dramático. Por ello, tengamos en cuenta que:
Tiestes y Atreo - Créditos: Gustavo Gorrini, gentileza Prensa TNA - TC. 


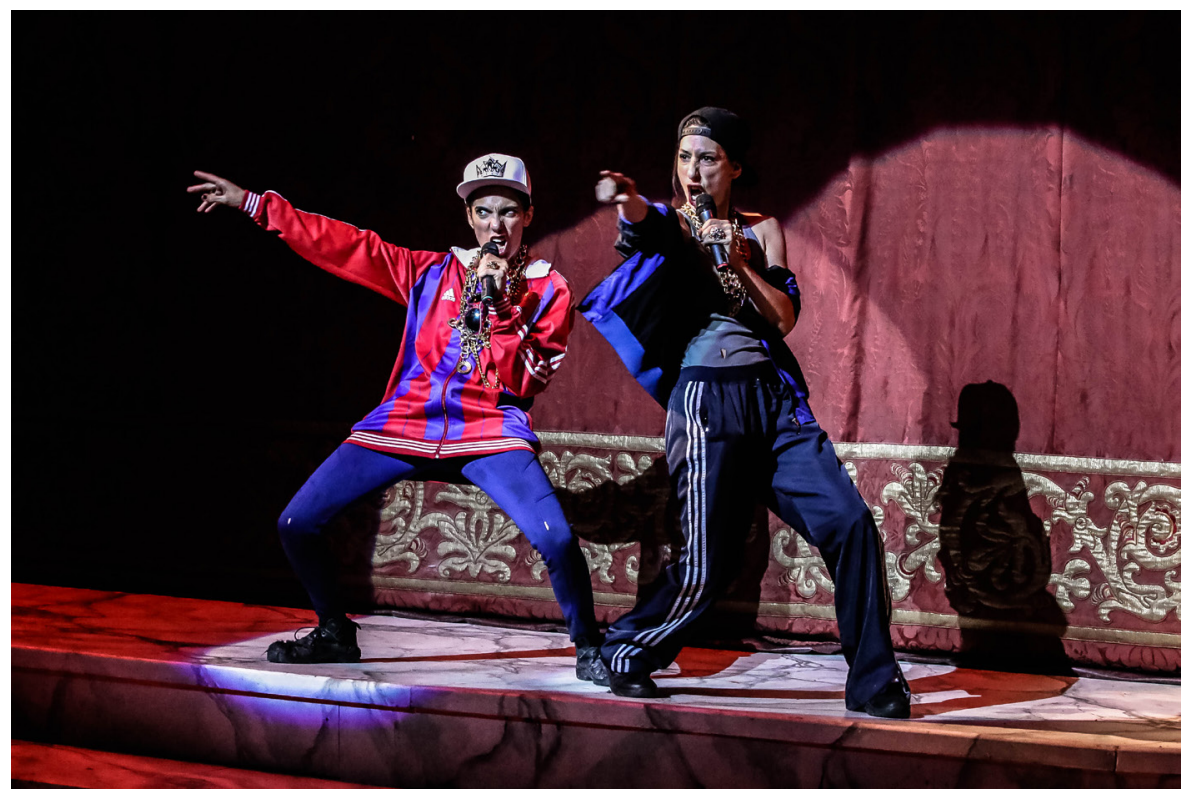

Las convenciones teatrales proveen al espectador informaciones y puntos de referencia necesarios para su trabajo inferencial en el esquema de cooperación interpretativa, propuesto en cada evento teatral. Por lo tanto, las convenciones implican un aprendizaje previo y una decodificación consciente por parte del receptor (Trastoy y Zayas de Lima, 2006:17)

Si pensamos en el sistema corporal, lo primero que resalta es el elenco conformado íntegramente por mujeres provocando una tensión con la obra clásica donde todos los personajes son masculinos. A la vez, destaca la versatilidad que manejan en cuanto al registro performático-actoral que varía según el momento de la obra; ya sea en la multiplicidad de los personajes que representan, la ejecución de los instrumentos musicales, las instancias de baile o de narración oral. La expresividad gestual, proxémica y kinésica resulta muy potente y remite a los estudios sobre el cuerpo realizados por Artaud a quien "no le interesan tanto la inteligibilidad de la palabra, como su valor metafísico, su capacidad de recuperar lo más primitivo, casi lo animal del ser humano" (Trastoy y Zayas de Lima, 2006: 50). Por otra parte, se advierten procedimientos de índole brechtiana como la ruptura de la cuarta pared, en el caso del coro, y del pacto ilusionista, en el de las niñas, algo que deja en evidencia el artificio teatral junto con el tránsito por el espacio de la platea y el uso permanente del proscenio como límite para comprometer al público. Por último, la declamación de los parlamentos pareciera vincularse más con la retórica antigua que con la enunciación del drama moderno. En suma, como vemos, la caracterización de los personajes es un híbrido resultante de la "contaminación de géneros", (Wehbi, 2013).

En cuanto al maquillaje y vestuario, tal como adelantamos, las niñas en el primer acto visten guantes blancos, sombrero y traje de azafata. Los payasos, la típica caracterización con nariz roja y maquillaje blanco. La Furia, borceguíes y el cuerpo embadurnado completamente en una mezcla viscosa de color marrón, mientras que los monstruos lucen el correspondiente disfraz pre-histórico. En el intervalo musical, Couceyro, Álvarez y una de las nenas visten indumentaria deportiva, cadenas doradas gruesas, anteojos y gorro de visera a tono con la onda rapper. En el segundo acto, las mismas actrices bien peinadas, llevan traje de vestir (pantalón y camisa), al igual que los guardias; por su parte, las hijas visten en un estilo punk (una con pantalón cuadrille, la otra con pollera negra y medias de red, ambas con remeras negras estampadas y zapatillas); el coro tiene ropa de gimnasio y la Furia y las nenas igual que en el primer
Tiestes y Atreo - Créditos: Gustavo Gorrini, gentileza Prensa TNA - TC. 
acto. Dada la exuberancia manifiesta en la utilización de este sistema recordemos que "el vestuario puede convertirse en el primer elemento que impresiona y conlleva una sensación visual de profunda significación" (Trastoy y Zayas de Lima, 2006:85).

Algo similar ocurre en el caso de los objetos: las tripas, los baldes de hojalata, la carrocería de los autos, el desodorante, las armas, la piedra gigante, la mesa, el cordero de oro, las tortas, las pantallas de televisión y el impactante cuadro, todo confluye en una profusión material que desde su facticidad configura una visual heterogénea que estimula al espectador imposibilitando anclar su mirada en un punto fijo.

En relación a la música esta juega un papel preponderante en los intervalos luego del primer y segundo acto. En efecto, podemos ver a la banda tocar en vivo y a las raperas montar un show hasta entonces inesperado, que incluye la destreza virtuosa de una de las nenas. Si bien las canciones aluden directamente a la temática central de la obra (los hijos devorados por sus padres), el efecto general es el de un shock disruptivo que distiende la representación dramática previa. Por otra parte, la ecuación vozpalabra-sonido resuena con fuerza en todos los personajes (incluidas las nenas que llevan micrófono) durante toda la función, generando un impacto duradero sobre la percepción del espectador. Pensemos que como indican Trastoy y Zayas de Lima "La voz es la fuerza material que pone en movimiento, dirige, detiene. Compromete todo el organismo y lo proyecta en el espacio extendiéndose más allá del cuerpo" (2006:189).

La iluminación de la primera parte es más colorida, resaltan los faroles amarillos y las luces rojas de neón, por otro lado, durante el desfile de payasos y sobre el final del acto la parrilla superior emana una luz gris tenue que genera una atmósfera pesada acorde con lo sucesos ya descriptos más arriba. En el intervalo, una luz horizontal a la manera del music-hall sigue a las cantantes de rap y a la pequeña bailarina. En la segunda parte, todo el escenario se ilumina claramente por medio de una luz blanca, que se fusiona con la luz de neón violeta, y, durante la lectura del texto, un foco vertical recorta a las narradoras del resto del escenario.

Para la puesta en espacio en Escila se construyó una escenografía que, según adelantamos, indica una temporalidad distópica posnuclear, mientras que, para Caribdis, un amplísimo comedor que evoca un gran palacio más ligado a la tragedia de Séneca.

Sintetizando lo expuesto anteriormente, la convergencia semántica de los diferentes lenguajes escénicos nos permite pensar cada acto como si fuesen opuestos complementarios.

\section{Collage intertextual}

Arribamos ahora al núcleo de nuestra propuesta analítica. Considerando el amplio bagaje cultural del director, no es de extrañar que en esta puesta (al igual que en otras) confluyan elementos provenientes de los más diversos horizontes culturales. Antes de enumerarlos consideramos adecuado, para dar mayor claridad a la exposición, encuadrar la puesta dentro de la 'tipología intertextual' que propone la clasificación de Pavis:

La puesta en escena intertextual asegura una necesaria mediación entre la autotextualidad de la primera y la referencia ideológica de la segunda (...) en particular para el texto dramático clásico, la puesta en escena no puede dejar de tomar partido en relación a los metatextos pasados (1988:30).

En la primera parte, las nenas se juntan en el bunker para ver películas retro-futuristas de Godzilla. Asimismo, los monstruos que aparecen recuerdan, con sus torpes 


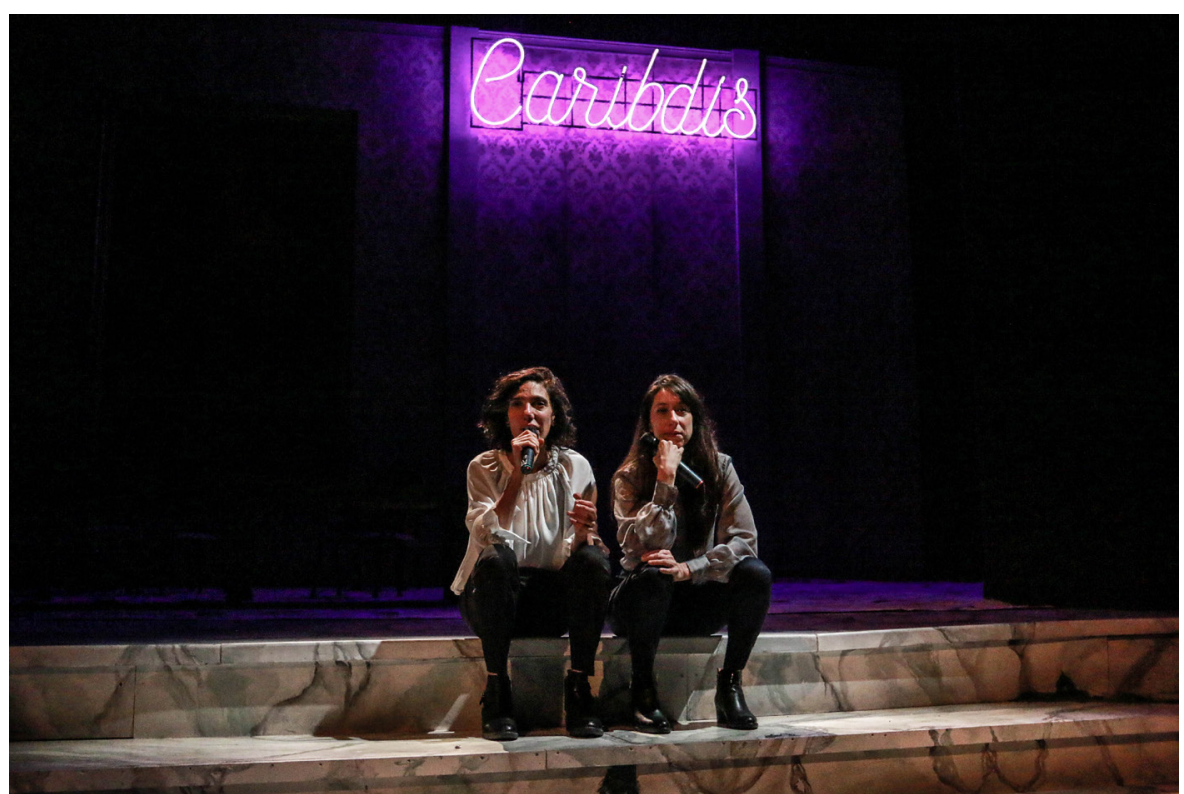

movimientos, a ciertos dibujos animados tipo anime japonés, acorde con el imaginario infantil, además la inscripción "dejad que vengan a mí" que se lee en el pórtico que atraviesan los payasos remite al "encuentro entre Jesús y los niños" (Mateo 19:13-16) de los Evangelios y, como sabemos, la cruz es el máximo símbolo del cristianismo.

El intervalo empieza con la banda interpretando "Come on up to the house" de Tom Waits y "Trouble everyday" del conjunto británico Tindersticks, ambas canciones pertenecientes al género rock. Con la irrupción de las rapers llegando desde la platea asistimos a la 'modesta proposición' que mixtura la prosa de Jonathan Swift (16651745) con el ademán hip-hopero del Bronx neoyorkino.

Luego, en el segundo acto, además de aparecer nuevamente pantallas plasma con imágenes de filmes de Godzilla, aparece también, casi en el centro de la escenografía, colgado, el imponente cuadro "Saturno" de Gorrini/Garelli, que satiriza, en el semblante de una mujer que come un sándwich de milanesa, el famoso óleo de Goya (1746-1848) "Saturno devorando a su hijo", que refiere al mito de Saturno (Cronos para la mitología griega), devorando a los hijos recién nacidos de su mujer Rea, por temor a que la progenie lo destronara. Sobre el final, a modo de coda, las actrices narran oralmente un cuento de Stig Dagerman "Matar a un niño".

Como queda claro, por todo lo dicho, la superposición incesante de citas en el orden temporal y espacial del espectáculo, por medio de los soportes artísticos más variados (danza, música, letras, plástica, cine, etc.), nos permite consignar la hipótesis de collage intertextual como el principio constructivo estructurante de la puesta. En este sentido, creemos que, para tal fin, el gesto autoral apunta a resemantizar, por medio del montaje, el conjunto de fragmentos arriba mencionados para así incorporarlos al contexto político-social vigente (capitalista, patriarcal, hetero-normativo y posmoderno) abriendo la posibilidad, según las competencias adquiridas por cada espectador, de que el público reconstruya esta "dramaturgia hecha de pedazos" (Wehbi, 2013) $y$, de este modo, alcanzar algún grado de significación relevante desde el punto de vista intelectual y emocional. Siguiendo las reflexiones que Pavis hace al respecto:
Tiestes y Atreo - Créditos: Gustavo Gorrini, gentileza Prensa TNA - TC.

La obra de arte moderna no existe hasta que no hallamos explícitamente despejado el sistema, hasta que no podamos diseñar el texto espectacular, disfrutar el placer de la deconstrucción, descubrir la dirección de todo funcionamiento escénico (1988:31). 


\section{Correspondencias posdramáticas}

Ateniéndonos al itinerario fijado al comienzo, procuraremos establecer una serie de correspondencias entre la puesta en escena de Tiestes y Atreo y algunos rasgos de la maquinaria teatral posdramática; para ello tomaremos como referencia el libro de Hans-Thies Lehmann, Teatro posdramático (2013), donde el teórico alemán sienta las bases que definen dicha concepción teatral.

Por un lado, la distinción en lo que hace al concepto burgués de teatro decimonónico (aristotélico, causal, mensaje unívoco, etc.) y la propuesta contemporánea del director (abierta, rizomática, de comunicación plural, etc.). Asimismo, en el cruce de discursos y formatos escénicos interdisciplinarios (performáticos, visuales, auditivos, etc.) que transitan en un espacio de fronteras difusas, liminales, "buscando nuevos caminos a partir del riesgo y la experimentación artística" (Wehbi, 2013), según define el autor su labor. Por otra parte, el lugar secundario del aspecto textual, que, si bien se ciñe al texto dramático de propia elaboración, no resulta por ello preeminente ni determinante como totalidad narrativa. A su vez, en la metodología de trabajo, procesual y de "negociación para con el actor en la construcción de su personaje" (Webhi, 2013), es decir desde una horizontalidad creativa de carácter colectivo y no desde la posición jerárquica del dramaturgo moderno quién proveía toda la información acerca de la obra. Al mismo tiempo, se advierten rasgos posdramáticos en la configuración de su estructura formal, esto es, en la autonomía discontinua de los actos y en cierta secuencialidad repetitiva al interior de los mismos (por ejemplo, en la circulación de los payasos y los monstruos, la reiteración del baile de la nena en el intervalo y en la redundancia de sentido en los monólogos de los personajes). También en la desmesura de los elementos, la densidad simbólica y el paroxismo dramático general, donde lo que se busca es estimular al espectador por medio de la multisensorialidad estética sin apelar a la búsqueda de sentido único.

Otro puente de articulación que podemos pensar es la autorreferencialidad y exhibición de los propios mecanismos de producción (un ejemplo clave en este sentido es la interpelación, a la que ya aludimos, que hacen las nenas a la Furia interrumpiendo el devenir ficcional), así como también en la interacción actor-público (el caso del coro o la narración oral) opuesta a la distancia prestablecida por el drama clásico. En suma, volviendo a Lehmann:

La heterogeneidad hizo tambalear las certezas metódicas que debían posibilitar la afirmación de causalidades a gran escala en el desarrollo artístico. Es necesario, por tanto, aceptar la coexistencia de conceptos teatrales divergentes que no pueden subordinarse bajo la preponderancia de un paradigma de representación único (2013:34)

\section{Conclusiones}

Propongo finalizar este trabajo haciendo un racconto de las instancias desarrolladas a lo largo de la exposición para verificar si efectivamente hemos alcanzado el objetivo trazado en el planteamiento inicial. Lo primero que hicimos fue enmarcar el argumento narrativo dentro del contexto histórico en el que apareció la pieza dramática de Séneca para observar cuál fue la lectura específica que hizo este del mito griego. Esto nos ayudó para diferenciar la ambigüedad originaria del mito en relación al acento moral que el dramaturgo romano le adjudicó a su fábula y también para pensar el posicionamiento crítico que asume la reactualización que lleva adelante la puesta de Wehbi en el tiempo presente. En segundo lugar, dimos una aproximación sobre la puesta del autor en el Teatro Nacional Cervantes para ofrecer un cuadro de situación concreto que nos permitiera anclar el análisis subsiguiente en su particularidad material e impedir perdernos 


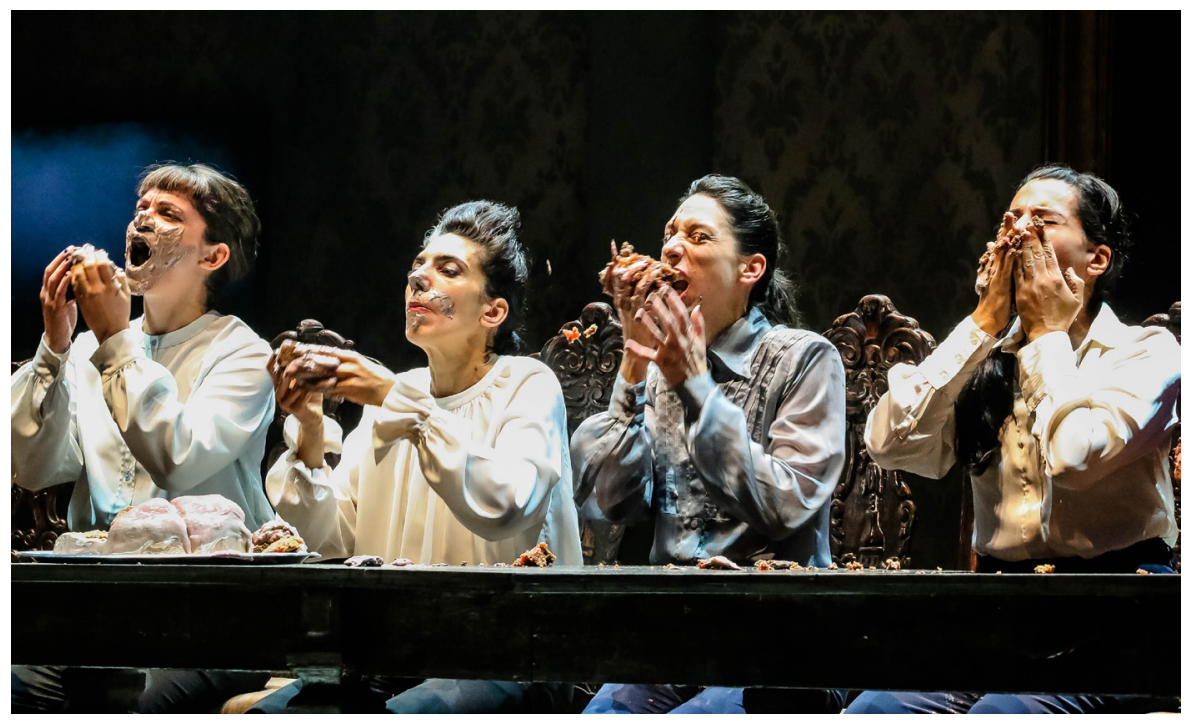

en elaboraciones meramente conceptuales y abstractas. En tercer lugar, realizamos un recorrido por el conjunto de los signos escénicos abordándolos desde un enfoque semiológico que permitiera dar cuenta de los posibles motivos que configuraron su diseño singular por parte del director. El cuarto apartado lo dedicamos a exponer las causas que nos llevaron a considerar la hipótesis que orienta el trabajo, la noción de collage intertextual como fundamento de construcción de la obra para desequilibrar, por medio de su poética, la desigualdad patriarcal vigente. Creemos que los argumentos allí esgrimidos fueron suficientes lo cual nos permite ratificar dicha conceptualización. Por último, establecimos algunos paralelismos entre la puesta en escena de Tiestes y Atreo y la concepción posdramática partiendo de la investigación que hiciera Lehmann. Ello nos brindó la posibilidad de reflexionar sobre los mecanismos de su producción lo cual complejizó aún más la elaboración de los ejes que vinimos trabajando.

Quisiera concluir con una frase apuntada en una de las entrevistas al autor, que creo, resume con elocuencia el compromiso que encara con su obra: "La estética es una ética y desde ese lugar entiendo mi producción artística, como toma de posición políticapoética frente a la cual relacionarme con el mundo" (Webhi, 2013).

\section{Ficha Técnica}

Elenco: Maricel Álvarez, Florencia Bergallo, Analía

Couceyro, Carla Crespo, Érica D’alessandro,

Verónica Gerez, Cintia Hernández, Mercedes

Quijeiro, Jazmín Salazar, Mìa Savignano, Lola

Seglin, Lucía Tomas.

Vestuario: Belén Parra.

Escenografía: Julieta Potenze.

lluminación: Agnese Lozupone.

Música y dirección musical: Marcelo Martínez.

Coreografía: Celia Argüello Rena.

Asistencia de dirección: Gladys Escudero.

Asistencia musical: Vanesa Del Barco.

Asistencia de iluminación: Cecilia Font Nine

Producción: Santiago Carranza.

Coach niñas: Aymará Abramovich.

Dramaturgia, puesta en escena y dirección: Emilio García Wehbi.
Tiestes y Atreo - Créditos: Gustavo Gorrini, gentileza Prensa TNA - TC. 


\section{Dibliografía}

» Barthes, R. (2003). Ensayos críticos. Buenos Aires: Seix Barral.

»Lehmann, H.T. (2013). Teatro posdramático. México: Innova.

"Pavis, P. (1988). “Del texto a la escena: un parto difícil”. Theatre Public (79).

»Séneca, L. (1980). Tragedias. Madrid: Gredos.

» Trastoy, B y Zayas de Lima P. (2006). Lenguajes escénicos. Buenos Aires: Prometeo.

\section{Diarios}

» Muñoz, A. (2018, 3 de Junio). “Cambiar futuro por pasado”. En Pagina/12. Radar.

\section{Sitios Web}

»Entrevista a Emilio García Wehbi, año 2013, Canal Getea. Consultado 19/6/2018, https://www.youtube.com/watch?v=av 05XYPozo 